\title{
Muñequitos rusos: la nostalgia y su contexto en la diáspora cubana
}

\author{
Russian cartoons: nostalgia and its context in Cuban diaspora
}

\author{
IVÁN DARIAS ALFONSO \\ Investigador independiente. ivan.darias.alfonso@gmail.com \\ Licenciado en Periodismo por la Universidad de La Habana (1994), cursó el \\ Máster en Estudios de Periodismo de la Universidad de Cardiff (2005) y se \\ doctoró en Estudios Latinoamericanos en la Universidad de Londres (2011). \\ Es ahora investigador independiente.
}

RECIBIDO: 28 DE ENERO DE 2015

ACEPTADO: 3 DE JUNIO DE 2015

Resumen: El presente artículo examina la importancia de la influencia soviética en la Cuba revolucionaria como incentivo para la vinculación afectiva transnacional entre emigrados cubanos, a través del análisis de las entradas e interacciones del blog Muñequitos Rusos, creado con el propósito de rescatar parte de la memoria colectiva de ese período reciente en la historia de la isla. Mi argumentación se enfoca al consumo y producción de "memorias mediáticas" en la diáspora, un espacio complejo que se caracteriza por la tensión que ejercen el país de origen y el de adopción, en la vida cotidiana de los emigrados y en sus constantes intentos por definir sus lealtades e identidad.

Palabras Clave: Muñequitos rusos, blogs, memoria colectiva, diáspora cubana, Cuba, URSS.

\begin{abstract}
This article discusses the importance of the Soviet influence in revolutionary Cuba as an incentive for transnational bonding amongst Cuban emigrants, by analysing the posts and interactions in the blog Muñequitos Rusos (Russian cartoons), created with the aim of recovering part of the collective memory of that recent period in the history of the Caribbean island. My argument focuses on the consumption and production of "mediated memories" in the context of diaspora a complex space characterised by the tension of the homeland and the host country in the emigrants' everyday life and in their constant attempts to define their loyalties and identity.
\end{abstract}

Key Words: Russian Cartoons, blogs, collective memory, Cuban diaspora, Cuba, USSR. 


\section{Introducción}

El advenimiento de plataformas como Blogger y Wordpress ha posibilitado que los emigrados cubanos promuevan blogs personales en muchos de los cuales sobresale el interés por sus vidas anteriores en la isla. La llamada blogosfera cubana floreció alrededor de los años 2007-2009 cuando emergieron una serie de bitácoras concebidas desde el territorio cubano, pero también desde las diversas zonas donde hoy residen emigrantes de la isla.

La gran mayoría de los blogs sobre Cuba en la diáspora han sido creados por autores residentes en Estados Unidos, los que, debido a la proverbial enemistad entre ambos países encontraron un público con un predecible interés político. Otros blogs también se originaron en Europa y Latinoamérica, de modo que podemos llamar "blogosfera cubana"1 a un espacio diverso con temáticas disímiles. No todos los blogs realizados por emigrantes cubanos tratan sobre el país y la experiencia migratoria e igualmente, no todos los blogs resultan una colección personal de anécdotas pasadas o un archivo de la memoria colectiva.

En el vasto catálogo de blogs cubanos, en el que predominan aquellos creados por periodistas y profesionales de los medios; sobresalen también un número importante de bitácoras alternativas, cuyos autores se han destacado por una reflexión sostenida acerca de aspectos como la autonomía y la ciudadanía en respuesta a estrategias de exclusión por parte de la oficialidad (Duong, 2013). Entre estos, Generación $Y^{2}$, escrito por Yoani Sánchez se tornó muy conocido y compartido a nivel mundial. Es bueno recordar que todavía en los inicios del fenómeno, los cubanos no tenían acceso libre a Internet o a los medios de prensa extranjeros, al menos de manera legal, de modo que la información sobre el acontecer nacional se mantenía bajo el estricto control de las autoridades gubernamentales.

Cuando las visiones alternativas sobre la realidad cubana y las noticias independientes originadas desde Cuba y su diáspora ganaron una amplia repercusión en la red, el gobierno de la isla reaccionó con su habitual mentalidad de estado de sitio, definiendo la emergencia del disentimiento

\footnotetext{
${ }^{1}$ Me refiero a la blogosfera como al conjunto de blogs realizados por cubanos de la isla o de la diáspora o a aquellos de marcada temática cubana, por ejemplo, los caracterizados por recopilar informaciones sobre la isla aparecidas en diversos medios, unidas a entradas de contenido propio o encargadas a colaboradores del blog, cuyo ejemplo más característico resulta Penúltimos Días. El bloguero Al Godar ha compilado una lista de más de 1200 “blogs sobre Cuba”, sin embargo, muchos de estos han sido borrados de la red o permanecen inactivos.

${ }^{2}$ Yoani Sánchez ganó gran popularidad luego de la apertura de su blog Generación Y. Ella recibió en el 2008 el Premio Ortega y Gasset de Periodismo concedido por el diario español El País y fue seleccionada entre las cien personas más influyentes del mundo por la Revista Time. En 2009 también recibió el premio Maria Moors Cabot de la Universidad de Columbia.
} 
digital como una campaña mediática contra la Revolución y más tarde con el término de ciberguerra $^{3}$.

Gran parte de este grupo de cronistas emergentes no solo coincide con la época caracterizada por el desarrollo de Internet como espacio para la creación y difusión de contenidos a gran escala, sino también con un período determinado en la historia de la emigración desde Cuba. Pertenecen, además, a una diáspora, que emergió a mediados de los 90, luego de conocidas crisis migratorias, como la de los balseros en 1994 y gracias a la creciente flexibilización de los trámites para viajar al exterior, por lo que tiene su origen en un contexto específico. Sin embargo, como nunca antes en la historia de la Revolución Cubana, su participación en vida social y económica del país caribeño, a pesar de distar de los niveles de impacto de otras comunidades transnacionales, incluso dentro del área latinoamericana, ha supuesto un cambio notable en la manera en que son percibidos hoy aquellos que abandonaron el territorio nacional.

\section{La diáspora cubana y sus orígenes}

La aparición de grupos de emigrantes cubanos, sigue a décadas de oleadas migratorias frecuentes que, desde el mismo inicio del gobierno revolucionario encabezado por Fidel Castro, y luego del establecimiento de incentivos como la Ley de Ajuste Cubano ${ }^{4}$, tomaron al territorio de Estados Unidos como destino final. No obstante, a mediados de los 90, cuando el bloque socialista del Este desaparece y Cuba pierde casi el 80 \% de su balanza comercial, muchos cubanos, la mayoría nacidos y formados en la era revolucionaria, optan por emigrar. Sin embargo, quienes lo hacen, se establecen no solo en Estados Unidos, sino también en países más cercanos lingüística y culturalmente como México, Argentina y España, o en otros de la Unión Europea (Alemania, Reino Unido, Francia e Italia, por solo citar algunos).

De manera que cuando se afianza Internet y surgen las plataformas de producción de contenidos ya señaladas, existe una gran cantidad de emigrados de la isla viviendo una existencia diaspórica, con todo lo que implica esa dualidad identitaria, según refieren varios teóricos (Tölölyan 1991; Saffran, 1991; Brah, 1996; Cohen, 1997). Se trata, no obstante, de una "comunidad” cuya situación con respecto al país de origen se torna compleja, pues carece del intercambio regular y

\footnotetext{
${ }^{3}$ Campaña mediática y ciberguerra son términos que pueden explicarse como derivados retóricos de la Batalla de Ideas. Antoni Kapcia (2008) considera dicha batalla como parte de la continua influencia que la ideología tiene en la sociedad Cubana. Ciberguerra responde especialmente a la mentalidad de estado de sitio que caracteriza los intentos gubernamentales por desestimar la aparición de voces críticas en Internet y vincularlas a los esfuerzos de Estados Unidos por destruir la Revolución Cubana.

${ }^{4}$ Establecida en 1966, la Ley de Ajuste Cubano otorga a los emigrantes que entren al territorio norteamericano el derecho a permanecer en Estados Unidos, con la posibilidad de obtener residencia al año de su llegada, además de otros beneficios.
} 
continuo de vínculos transnacionales. No obstante Velia Cecilia Bobes ha destacado que a partir de la primera década del siglo XXI, los contactos entre emigrados y su país de origen han propiciado "la transnacionalización del imaginario y el universo de valores de la sociedad que se manifiesta en cambios simbólicos importantes" en Cuba (Bobes, 2012: 119).

Es necesario aclarar que solo en enero del 2013 los ciudadanos cubanos fueron autorizados a viajar libremente, siempre y cuando le hubieran sido otorgadas las correspondientes visas para el país de destino. Hasta 1989, la emigración desde la isla tenía un carácter más permanente, pues quienes salían a establecerse fuera de las fronteras lo hacían "para siempre" 5 . Por otra parte, únicamente aquellos que eran seleccionados para misiones oficiales (económicas, de asistencia médica, académicas, deportivas y culturales) podían abandonar el territorio nacional por motivos de viajes. A inicios de la década del noventa con el auge del turismo internacional, muchos cubanos emigraron tras conocer y contraer matrimonio con extranjeros. Ya para ese tiempo, las autoridades de la isla habían flexibilizado, en alguna medida, los trámites migratorios. Sin embargo, aún eran necesarios el Permiso de Salida ${ }^{6}$ y el de Residencia en el Exterior para garantizarle a quienes emigraban por esta vía, el trayecto y de ida y vuelta y la posterior entrada al país.

La gran mayoría de los emigrantes de esta diáspora que nos ocupa la componen los nacidos a finales de los 60 y en los 70 e inicios de los 80 . Se trata de generaciones que, formadas en el período revolucionario y en los años de relativa estabilidad económica, si se compara con el llamado Período Especial $^{7}$, partieron a finales del siglo XX. Son ellos, fundamentalmente, a quienes el advenimiento de Internet y los blogs, los encuentra con una significativa experiencia de haber vivido años fuera de su país de origen. De manera que, como se explicará a continuación, los blogs y posteriormente las redes sociales resultarán herramientas y espacios favorables para el intercambio de memorias sobre el pasado común, previo al abandono del país, en el que Cuba pertenecía al bloque de países bajo la influencia de la Unión Soviética.

En el presente artículo analizo la importancia de los llamados muñequitos rusos como incentivo colectivo para la construcción, revisión y manifestaciones de la nostalgia del período soviético. Para ello centro mi análisis en los posts e interacciones del blog Muñequitos Rusos, como

\footnotetext{
${ }^{5}$ El término correcto es “salida definitiva” según la Ley de Migración vigente hasta el 16 de Octubre de 2012, cuando fue modificada por el Decreto-Ley No. 302. Bajo las nuevas regulaciones, los cubanos que viajaban al exterior podían permanecer hasta 24 meses, sin que fueran declarados "emigrados" por las autoridades de la isla.

${ }^{6}$ El Permiso de Salida era entregado por las autoridades migratorias cubanas como ultimo trámite antes de poder viajar al extranjero. El Permiso de Residencia en el exterior, autorizaba a sus portadores a residir en el extranjero y a viajar a la isla sin ningún tipo de restricción, siempre y cuando no hubieran tomado parte en actos hostiles contra la Revolución Cubana.

${ }^{7}$ Período Especial en Tiempos de Paz fue el nombre oficial con el que las autoridades cubanas designaron al período que siguió a la desaparición del campo socialista (1989-1995)
} 
parte de un contexto mayor (blogosfera cubana) que a mediados de los 2000 facilitó la identificación y emergencia de un sector de la diáspora cubana que mostró, a través de su activa presencia online, la influencia del período soviético en su formación y señas de identidad.

Considero que los muñequitos y las interacciones que propician, pueden calificarse como parte de un conjunto de prácticas transnacionales que incluyen productos comunicativos y/o originados en los medios de comunicación. Como demostraré en el análisis del blog, tanto la autora del mismo como los visitantes, participan de un proceso que va desde la creación personal de recuerdos puntuales, al intercambio colectivo de memorias culturales. Aquí me refiero al concepto de “memoria cultural” definido por Astrid Erll (2011) como la interacción del presente y el pasado en contextos socioculturales.

Me he centrado en un blog creado en la diáspora, por las posibilidades que este espacio brinda en cuanto a tecnologías y recursos para los emigrados cubanos, a niveles prácticamente incomparables con los de sus compatriotas en la isla, dados los consabidos problemas de acceso mayoritario a la Internet en $\mathrm{Cuba}^{8}$. Entiendo que la vuelta de los animados se inscribe en un contexto global donde fenómenos como la Ostalgie (Estalgia) son materia de estudio académico, pero también de conocimiento general en un mundo notablemente interconectado. Sin embargo, creo -como argumentaré más adelante - que esta posible versión de la Ostalgie Caribeña, como algunos la han definido (Reyes 2011) se origina primero en la diáspora, donde la memoria "se produce" y se traslada luego hacia el país de origen -en lo que constituye un flujo característico del contexto diaspórico (Cohen, 1997), donde la memoria “se consume”.

El artículo se divide como sigue: en la próxima sección explico brevemente los muñequitos rusos en el contexto de los medios de comunicación cubanos durante el período soviético. Aquí destaco también cómo se convirtieron en un referente cultural colectivo para varias generaciones de cubanos. Tal impacto presupone un lugar en la memoria colectiva; por tanto, en la siguiente sección expongo el marco teórico en el que sustenta mi análisis del blog y sus interacciones, para debatir sobre las memorias mediáticas. La siguiente sección se centra en el análisis del blog desde la perspectiva de su autora y allí revelo la relación entre la memoria y la construcción del pasado común. Luego comento las interacciones del blog a través de sus visitantes y cómo los emigrados intervienen en la re-construcción de las memorias generacionales y colectivas, ahora desde la perspectiva de la diáspora.

\footnotetext{
${ }^{8}$ El acceso público a Internet en Cuba solo es posible, de manera legal, a través de salas de navegación del monopolio estatal ETECSA, donde los que acceden deben pagar la hora de conexión a CUC 4.50 (pesos convertibles), el equivalente a CUP 125 (pesos cubanos). Téngase en cuenta que en el 2013 el salario medio en Cuba era de CUP 471 (ONE, 2014). No obstante, como varios autores señalan (Bobes, 2012; Duong, 2013), es posible conectarse a Internet por medio de cuentas piratas.
} 


\section{Los dibujos animados y su poder evocador del pasado común}

Con el nombre de "muñequitos rusos" puede designarse en Cuba a un amplio catálogo de dibujos animados provenientes del antiguo campo socialista en el que sobresalen los producidos por los Estudios Soyuzmultfilm de la extinta URSS. Los cubanos consumían tales animados de manera organizada, como parte de la programación infantil del Canal 6 de la Televisión Cubana, que se iniciaba a las 6 pm. con un bloque de "muñequitos" hasta las 7 p. m., hora en la que alternaban series animadas con otros programas de producción nacional, seguidos de otro seriado conocido popularmente como las “Aventuras” de 7:30 a 8:00 p. m.

Esta disponibilidad de animados y programas infantiles debe entenderse en el contexto mediático de la Cuba revolucionaria y "soviética" en este caso, donde los medios de comunicación seguían el Modelo de la Propaganda y formaban parte de la labor ideológica del Partido Comunista. Además, la producción y distribución de contenidos y prácticas culturales destinadas a niños y jóvenes siguieron las ambiguas y limitadas líneas del quehacer cultural en el país, definidas en las "Palabras a los Intelectuales" de Fidel Castro en $1961^{9}$ y posteriormente en el Primer Congreso de Educación y Cultura diez años después.

Un breve análisis de las políticas emanadas de tales eventos sirve para caracterizar los valores formativos y didácticos que las autoridades decidieron promover en los medios (Casal, 1971), en especial de la Televisión. Asimismo, conviene recordar que los niños cubanos que nacieron y crecieron desde finales de los 70 hasta el 89, lo hicieron en un ambiente más bien precario en cuanto a la producción televisiva. El país, durante esas décadas, contó solo con dos canales de televisión y aproximadamente unas 6 horas diarias de programación, que se ampliaba a 12 horas los fines de semana. A pesar de reconocibles esfuerzos por la creación de contenidos propios, la Televisión Cubana nunca pudo competir en número de programas y series y animados, con sus similares del campo socialista. De manera que durante las décadas señaladas, era muy frecuente la repetición de programas y sobre todo de animados, lo que, como se explicará más adelante, contribuyó a que más de una generación de cubanos dispusiera de un repertorio común de imágenes y temáticas en dibujos animados.

\section{Blogs y Memoria Cultural}

Los estudios iniciales que definen la memoria como un fenómeno social señalan la importancia de analizar al individuo y al grupo, y al papel que juegan sus respectivas interacciones en procesos de formación de la identidad. Maurice Halbwachs afirma que "ninguna memoria es posible fuera de los

\footnotetext{
${ }^{9}$ Resumido por la frase “Dentro de la Revolución todo; contra la Revolución, nada”, este famoso discurso de 1960 ha sido constantemente invocado como la plantilla según la cual se define la política cultural de la Revolución.
} 
marcos usados por las personas que viven en sociedad para determinar y recuperar sus recuerdos" (1992: 43, mi traducción). Para él, la posibilidad de recordar implica una conexión entre sistemas individuales de ideas sobre el pasado y aquellas provenientes de los círculos del individuo (familia, religión, clase social), de ahí el término memoria “colectiva”, el recuerdo acumulado de un pasado compartido por las personas en un marco social. Recordar, para Halbwachs, se torna una experiencia social porque los diversos grupos que componen la sociedad son capaces de reconstruir el pasado en cualquier momento (1992: 182, mi traducción). Yo añadiría que el proceso de guardar y recuperar los recuerdos de eventos pasados resulta esencial para definir identidades personales debido a su potencial para examinar la interacción del individuo con el grupo y entre los diversos grupos de una determinada sociedad.

Para José van Dijck (2007), las “memorias mediáticas" son las actividades y objetos que producimos y de las que nos apropiamos mediante las tecnologías de los medios de comunicación, para crear y recrear el pasado, el presente y el futuro de nosotros mismos con relación a los demás. Ella concibe los actos de recordar como interacciones entre los individuos y sus círculos sociales, lo que destaca la importancia dada a lo individual y lo colectivo en procesos de rememorar un determinado pasado común.

Así, aunque los diferentes medios de comunicación experimentaron un acelerado desarrollo en la segunda mitad del siglo XX que repercutió en una continua búsqueda y producción de la memoria colectiva, la llegada de Internet y sobre todo de las plataformas para crear contenidos en línea como Blogger y Wordpress socializó a gran escala dicha producción de memorias.

Para van Dijck (2007) los blogueros, como los diaristas de épocas anteriores, participan de procesos que ayudan a definir sensaciones subjetivas e identidades a través de conexiones afectivas que ayudan también a adquirir conciencia de uno mismo con relación a los demás. De ahí que el análisis de los blogs y sus interacciones, al menos en los años previos a la consolidación de las redes sociales, sea tan pertinente para teorizar sobre la memoria colectiva, la emigración y la construcción de la identidad, en tiempos de globalización.

Antes de pasar al análisis del blog, conviene explicar otras dos peculiaridades relativas al pasado y a la emigración como fenómeno en el contexto de la Cuba revolucionaria. Hay que recordar que luego de la toma del poder por Fidel Castro y sus seguidores, el año 1959 pasó al imaginario nacional como la línea divisoria entre el pasado burgués y el futuro socialista. Como parte de la labor ideológica del gobierno revolucionario y luego de su adhesión al bloque socialista liderado por la URSS, los medios de comunicación cubanos lograron crear un paradigma representacional de la sociedad cubana y la historia nacional previa al triunfo revolucionario. El presente que les tocó vivir a muchos de los actuales blogueros de la diáspora estuvo también influenciado por esa representación del pasado como burgués y atrasado, y del presente y futuro como reflejo, no siempre exacto, de la 
nación en vías de desarrollo. Tal noción de lo "anterior" y lo "presente” resultó además fundamental para el afianzamiento de una noción de identidad nacional en la que la definición de patria se equiparó con la de Revolución Cubana (Hernández-Reguant, 2009), de manera que cualquier desviación de tal limitada concepción justificaba no solamente el calificativo de contrarrevolucionario, sino también el de "anticubano".

Con este último adjetivo, la prensa oficial y las autoridades, denominaron durante muchos años a la comunidad cubano-americana de Estados Unidos, resultado de varios influjos migratorios. A diferencia de las generaciones formadas en la isla, los cubano-americanos construyeron sus propias nociones de identidad y nación, con mínima o ninguna influencia de lo acontecido en la Cuba post-1959 (García, 2007). Quienes emigraron en los 90 y accedieron a un mucho más amplio catálogo de expresiones de cubanidad, se enfrentaron a un probable proceso de negociación de lealtades. Contaban ahora con dos versiones contrastantes de lo que constituían la nación y la identidad nacional y, por añadidura, cargaban con las influencias de un pasado común en la isla, marcado por la influencia de un país multinacional y potente que había dejado de existir: la Unión Soviética.

\section{La memoria en línea}

El blog Muñequitos Rusos fue creado por Aurora Jácome (bajo el pseudónimo Akekure) en noviembre de 2005, en lo que podríamos considerar el período inaugural de las bitácoras personales. Desde su inicio y hasta abril de 2010, la autora publicó entradas con cierta regularidad. El blog continúa online, su estado podría calificarse de inactivo, pues no se han publicado nuevos posts, aunque en los archivados es posible encontrar comentarios que datan de fechas posteriores al "cierre" y hasta recientes como 2014. Con este dato quiero señalar la función de referencia sobre el tema, que todavía cumple esta bitácora personal, que desde su primer posts ganó una audiencia interesada en su eje temático y que luego de sus años de mayor actividad, aún logra atraer a visitantes que no solamente acceden a las entradas publicadas, sino que también leen la gran cantidad de comentarios archivados.

Damaris Puñales Alpízar (2012) utiliza el término de una comunidad sentimental soviéticocubana, para referirse a los cubanos formados durante el período de influencia de la URSS en la isla. Como rasgo característico de tal comunidad, Puñales Alpízar cita "sus vínculos sentimentales que convergen en ese territorio por excelencia de la nostalgia que es la infancia y la primera juventud" (2012:112). Quienes acceden al blog pueden ser estudiados como parte de dicha colectividad, pues como ya he explicado anteriormente, me interesa concebir el blog como un espacio ideal para la creación de vínculos afectivos transnacionales entre los cubanos de la diáspora, 
de ahí que conceda la importancia justa a los comentarios e interacciones para el consiguiente análisis del blog.

Desde el post inicial, Akekure enfatiza en la naturaleza traumática que entraña el asociar los muñequitos rusos con las memorias de su país de origen. La noción del trauma (personal, generacional) se justifica en el propio acto de consumir animados, cuyos argumentos -se afirma escenificaban conflictos emocionales contados a partir de un notable interés de sus creadores por reflejar aquellos aspectos menos optimistas y edificantes de la vida cotidiana. Según aclara Jácome: "eran esas tristes y traumáticas historias aderezadas de su correspondiente banda sonora al más puro estilo ruso-depresivo." Con esta primera entrada, que recibe más de 250 comentarios, el tema de los muñequitos y su incidencia en la memoria colectiva de los emigrados, no podía haberse introducido de mejor manera.

Como afirma Jacqueline Loss, los muñequitos rusos se han convertido en un importante marcador para las generaciones de cubanos nacidos a finales de los 60 y 70 (Loss 2003). Y en su intento por desentrañar esa importancia como marcador identitario, la autora del blog nos ofrece además en este post inicial, claves para entender esa búsqueda del pasado. Como asegura aquí y en un artículo posterior sobre el vínculo generacional con los animados (Jácome 2011), la necesidad de repasar sus memorias obedece, por una parte, al contexto de la diáspora y por la otra, al mismo acto de escribir en el blog sobre el pasado común.

Menciono la diáspora porque en los objetivos del blog, se puede identificar el ya referido interés del emigrante por identificarse con respecto a sí mismo y a quienes conforman su día a día en el país de acogida, es decir, los locales y otros emigrantes (Brah, 1996). La autora aclara que emigró con sus padres a los 16 años. En su caso las memorias de Cuba pertenecen específicamente a un período de formación (infancia y adolescencia). Luego, en el artículo mencionado, Jácome explica que "sintió que su adaptación no era completa" (2011: 27), de ahí la justificación para la creación del blog y la narración y el compartir de sus memorias. Bloguear en este caso -como bien asegura van Dijck, facilita entonces la creación de versiones digitales de los recuerdos que a la vez se tornan objetos factibles de compartirse en red, concebidos en el marco común de la Web y en interacción constante con otras personas e incluso con públicos anónimos (Van Dijck, 2007: 48).

En materia de estructura las entradas del blog dedicadas a los animados -pues aparecen otras donde Jácome reflexiona sobre la memoria y los viajes - siguen un patrón bastante similar. La autora se refiere al dibujo animado con su ficha técnica: fecha de realización, principales animadores, autores de la música. En mi opinión tal detalle ayuda a situar a los muñequitos en un contexto que necesariamente conduce al pasado. Lo que sorprende a Jácome y también a muchos comentaristas del blog, es la antigüedad de gran cantidad de los dibujos y cortos animados que los cubanos vieron e incorporaron a sus memorias los cuales, en algunos casos, se proyectaban en la TV cubana hasta treinta años después de haberse realizado. Por ejemplo, en plenos años 80 , los niños cubanos podían 
sentarse frente a sus televisores y apreciar cortos como "El antílope dorado" (Золотая Антилопа, Lev Atamanov, Soyuzmultfilm) realizado en 1954, "Plumita de oro" (Золотое Перышко, Renata Mirenkova, Soyuzmultfilm), en 1960 o "Rikki-Tikki-Tavi” (Рикки-Тикки-Тави, Alexandra Snezhko-Blotskaya, Soyuzmultfilm), en 1965.

Es bueno aclarar que, como afirman muchos comentaristas del blog, acercarse a los recuerdos infantiles desde la distancia de los años y desde el espacio que constituye la diáspora, sugiere cierto escepticismo. En ese sentido, estimo que la inclusión de la ficha técnica complejiza el revisitar las memorias, pues aporta nuevos datos para situar a los animados y al acto de verlos en un contexto diferente al que refieren los recuerdos. Conviene destacar que los animados se proyectaban en los canales de la isla, doblados al español y muchas veces tal función la cumplía un equipo de actores de la propia televisión isleña. Además, aunque en la actualidad y gracias a Internet, los emigrados pueden acceder a versiones renovadas de aquellos animados; en la isla, en los años 70, la mayoría se acostumbró a verlos en blanco y negro, posiblemente en un aparato de fabricación soviética, el famoso modelo Krim 218. Así que en la memoria, el recuerdo de los muñequitos se relaciona con una representación específica en cuanto a imagen y sonido y -como afirman muchos - las versiones recientes que pueden ver en el blog o en sitio como Animator.ru o YouTube, carecen o del familiar doblaje de antaño o de la expresividad de la ausencia de colores.

Y es que, como demuestran las interacciones del blog, los animados no sólo quedaron en la memoria por sus temas o características técnicas, ya que, por ejemplo, ciertos parlamentos de sus personajes pasaron al habla común de niños, adultos y luego de generaciones de cubanos. Tanto en la isla como en la diáspora, frases como "Deja que te соја" (Ну-Погоди!, Viacheslav Kotiónochkin, Soyuzmultfilm, Studio 13, Christmas Films, 1969-2006) o "Es Fantito, va a regar la espina” (Фантик, Yefim Gamburg, Soyuzmultfilm, 1975), entre otras muchas sacadas del amplio repertorio de los dibujos animados, hoy sirven como marcadores simbólicos de al menos tres generaciones de cubanos. Por eso me refiero al papel de los animados como incentivos para la vinculación afectiva entre emigrados, porque constituyen referentes conocidos tanto en el contexto del país de origen como en la diáspora.

A las entradas relativas a los animados, la autora adiciona otras en las que comparte sus reflexiones no solamente acerca otras referencias culturales comunes durante el período de influencia soviética. Hay en estos escritos una intención manifiesta de equiparar al pasado con un sistema de valores que la autora describe como "culturalmente enriquecedores" y del cual los animados eran su más fiel reflejo:

A veces me pregunto si vivimos en una sociedad que nos ha obligado a desenterrar nuestros recuerdos para soportar el triste y desalentador presente y no pensar demasiado en el futuro incierto que nos espera. (Interpretando a Cheburaska, post publicado por Akekure 13 julio 2006) 
Como puede apreciarse, los muñequitos además de caracterizar una época están imbuidos de significados, justificables también según el Modelo de la Propaganda, como parte de los esfuerzos de las autoridades por formar hombres y mujeres socialistas, lo que en el contexto de la isla se asocia con el "hombre nuevo", que fuera definido por Ernesto Guevara en su ensayo de 1964. A ellos les correspondía edificar el utópico mundo futuro, que en Cuba se enmarcaba también en un ideal colectivo en el que la nación se proyectaba como desarrollada, gracias a notables adelantos científicos: centrales electronucleares y viajes al $\operatorname{cosmos}{ }^{10}$. Tales promesas e ideas generacionales, tras la desaparición de la URSS, se esfumaron -como los muñequitos de la TV - del discurso oficial de la isla.

Para la autora, sin embargo, los cubanos que sienten nostalgia por los animados rusos, "añoran algo menos material y más abstracto y espiritual”. Con esta caracterización, se alude a la presencia de intereses comunes en una parte considerable de la diáspora, que sobrepasan el mero hecho de proceder del mismo país. Jácome presupone la posible identificación de marcadores distintivos que, en mi opinión, facilitan la vinculación afectiva transnacional entre los emigrados cubanos, aunque a ello me referiré en detalle en la próxima sección del presente artículo.

Antes de finalizar esta quisiera destacar que fue intención de la autora no incluir "la política" en su blog. Desde el inicio a Jácome le interesa definir su espacio como un sitio para compartir memorias e intercambiar sobre el pasado común, sin caer en divergencias políticas pues a eso se dedican “los mayores de 50". Tal vez, el hecho de que esté basada en España y no en Estados Unidos influya en su intención de establecer estos límites. Mette Berg (2011) ha realizado durante varios años investigaciones antropológicas con cubanos en España y concluye que existe en estos un interés por distanciarse del origen político de la comunidad cubano-americana cuando los emigrados escogen al país ibérico destino para establecerse. Sin embargo, como expondré al analizar las interacciones del blog, el debate sobre la connotación política que tenían los muñequitos no depende del lugar donde residen quienes comentan.

\section{De la vivencia personal a la memoria colectiva}

De igual modo que el post inicial del blog parece haber sentado las bases del sitio y su objetivo, también sirve para valorar el impacto de los muñequitos y los recuerdos asociados a ellos, si atendemos al número de comentarios dejados en el blog. Justo desde esa primera entrada emerge una audiencia interesada en compartir experiencias y memorias, pero también datos técnicos, nombres

\footnotetext{
${ }^{10}$ Definida como “La obra del siglo”, la Central Electronuclear de Juraguá (Cienfuegos) comenzó a construirse en 1982 hasta que las autoridades decidieron paralizar las obras en 1992. Hasta el momento el proyecto de terminar la central ha sido abandonado. El 18 de septiembre de 1980, el cubano Arnaldo Tamayo se convirtió en el primer cosmonauta de la isla, al viajar en la nave Soyuz 38 desde Kazajstán como parte del Programa Intercosmos, también de la URSS.
} 
de olvidadas o raras producciones de animados socialistas y más adelante prácticas culturales, costumbres y actividades comunes del día a día de quienes vivieron durante el período soviético en la isla.

Los comentarios revelan cuán disperso está el público, pues los visitantes mencionan el país desde donde acceden, que puede ser tan familiar como los del área Latinoamericana o más exóticos, si nos fijamos en destinos inusuales en las trayectorias migratorias de los cubanos, por ejemplo, Letonia o Irlanda. Además, al inicio quienes comentan, citan el descubrimiento del blog en términos bien emotivos, en los que se repite con la admisión de haber llorado al recordar las imágenes de la niñez:

es bueno muy bueno saber que no soy la única a la que se le aprieta el pecho y suelta unas lagrimas cuando recuerdo los muñequitos rusos (Comentario dejado por Elizabeth, 23 junio 2006 7:07 p. m.)

En realidad me consideraba anormal por pensar que eran buenos, o al menos eso pensaba en aquel entonces(era lo único que había), pero recordarlos me ha hecho llorar un poco (Comentario dejado por alessandro, 14 diciembre 2008, 4:58 a. m.)

Ya en los primeros seis meses de actividad en el blog, se pueden identificar -además de un creciente interés por las visitas - a un grupo de habituales comentaristas que no solamente interactúan con el post de turno, sino que proponen nuevos vínculos y sitios donde descargar animados y películas. Es bueno aclarar que a medida que el blog aumenta en profundidad, se incluyen ya producciones animadas procedentes de otros países, incluso capitalistas, como Francia, España y Japón, y que ante los reclamos de la audiencia, la autora también escribe al respecto, presentando historias vinculadas a estos otros animados y filmes no-rusos.

Me interesa resaltar las interacciones registradas como comentarios, porque evidencian la identificación con un pasado común, en el que -según Halbwachs (1992)- resulta fundamental a la hora de conformar sus identidades. Se puede hablar de una memoria colectiva, porque el recuerdo del pasado refleja una identidad de grupo (cubanos) o colectiva que va más allá del simple hecho de que la bloguera y la mayoría de quienes comentan vivieron su infancia y adolescencia en el período soviético de la Cuba revolucionaria. Ellos fueron educados y formados en un sistema político en el que -como también afirma Halbwachs - los recuerdos del pasado se organizaron de manera que estos "pudieran ajustarse a las condiciones variables del equilibrio de la sociedad" (1992, p. 183, mi traducción).

y creo que estos "muñequitos" se metieron en lo mas profundo de nuestro subconsciente, e influyeron en nuestro comportamiento futuro y en la forma de ver la vida. No eran dibujos animados con transfondo político, eran mas sanos y enseñaban muchos valores morales, sin 
violencia y cosas sin sentido, además de fomentar nuestros deseos de conocer nuevas cosas y viajar. (Comentario anónimo 19 marzo 2007, 8:56 p. m.)

Por otro lado, no se puede negar que todo dibujo animado puede ser acusado de "adoctrinamiento" en un sentido amplio. Todos transmiten actitudes e ideas preconcebidas que resultan aceptables para la sociedad que los produce. Algunos son más evidentes (El tío Stiopa) y otros más sutiles, hasta el punto de que no podría señalarles nada (Cómo los cosacos salvaron a sus muchachas), pero todos transmiten "algo", que no es sólo político, sino cultural, entendido en el sentido más amplio posible. (Comentario dejado por Gabriel Syme, 25 junio $2006,6: 30$ p. m.)

Los comentarios anteriores muestran que el acercamiento al pasado no es simplemente nostálgico, sino más bien crítico. Ambos visitantes ofrecen su reflexión personal sobre el período soviético, que como uno más en la reciente Historia de Cuba, no puede disgregarse de la etapa revolucionaria. En ese contexto el pasado adquirió gran importancia como agente cohesivo y las nociones de identidad colectiva que garantizaban la unidad se impusieron sobre aquellas que aseguraban individualidad y diferencia. Ahora, desde la diáspora, el pasado vuelve a tener su importancia como agente aglutinador, aunque aparece más limitado por el espacio del blog y su objetivo temático.

Conviene aclarar que ya para esa época la blogosfera cubana se había consolidado en Internet y que muchos de aquellos iniciales blogueros le dedicaron gran cantidad de posts a narrar sus vivencias como habitantes de su país de origen, matizadas por la experiencia de la emigración. De cualquier modo, los comentaristas del blog demuestran que su memoria del período soviético es un esfuerzo colectivo, en el sentido de que no basta solo la opinión de la autora para conformar versiones de un pasado común, sino que este se rememora gracias al aporte de los demás.

Los recuerdos de Akekure dejan de ser únicamente suyos para socializarse en las interacciones del blog. Como afirma Erll (2011), las memorias personales solo pueden ganar una relevancia social a través de la representación mediática y su distribución. El blog, y sobre todo sus interacciones, sirven aquí como constancia de las recordaciones que, gracias a Internet, se distribuyen y consumen. Es bueno aclarar también que en su período de mayor actividad el blog trascendió a la isla, donde varias cubanos, incluso aquellos que nunca habían salido de Cuba, se reconocieron en el recuerdo colectivo de la nostalgia por los muñequitos rusos.

Como he mencionado anteriormente, el aporte colectivo de las memorias del período soviético no se quedó en la influencia de los dibujos animados. Varios visitantes aportan vivencias sobre el acontecer diario de aquellos años, que además de coincidir con los de las subvenciones soviéticas y la 
ayuda del CAME ${ }^{11}$, también quedaron en el imaginario nacional de los cubanos, como los de la mejor calidad de vida. Estimo que tal aseveración es solo posible si se compara este período con el que siguió a la desintegración de la URSS, cuando los cubanos tuvieron que soportar años de escasez de alimentos, cortes de electricidad, epidemias y disminución considerable de productos y servicios.

Por tanto, el recuerdo de los muñequitos permite el revisitar el pasado con un doble propósito, el intercambio de memorias sobre la infancia y adolescencia y de una noción de país más cercana al discurso oficial que lo caracterizaba como "en vías de desarrollo". Sin duda tal asociación refleja también la equivalencia entre patria y Revolución Cubana, que ya hemos mencionado en la introducción y que a la vez resulta esencial para definir lealtades e identidades. Además, como afirma Ariana Hernández-Reguant, a inicios de los 90 en el discurso de la sociedad cubana, los elementos constitutivos de la identidad nacional apelaban más a la importancia de considerar a la isla como una comunidad cultural y étnica, antes que una nación definida por un sistema político específico (2009:72).

Refiriéndose a "cierta" nostalgia por lo soviético y en especial a los dibujos animados, Dean Luis Reyes (2011) estima que el acto de recordar rebasa los marcos testimoniales y adquiere el significado de un lamento generalizable al entorno social de una época y sociedad. En su opinión tampoco queda claro si las influencia que los muñes dejaron en los jóvenes cubanos se valoran positiva o negativamente. Los comentaristas del blog, por su parte, coinciden en destacar los aspectos artísticos y formadores de los animados, aunque admiten que, por lo general, sus temas y la realidad que representaban distaban bastante de la vida, el clima y la cultura de la isla caribeña. Si la mayoría no indaga en el pasado común, con un interés más crítico, se debe en parte al esfuerzo de la autora por mantener el blog y los comentarios libre de antagónicos debates políticos. No obstante, aparecen en el blog, opiniones que cuestionan la naturaleza adoctrinadora de los animados e incluso rechazan y juzgan a quienes se identifican con los muñequitos y defienden sus mensajes e influencias en su vida pasada en la isla.

\section{LA FELICIDAD CONSISTE EN GRAN MEDIDA EN LA IGNORANCIA ${ }^{12}$, por eso éramos felices en nuestra niñez, ignorábamos demasiadas cosas y aunque este mundo que inventamos los hombres no es perfecto, en cualquier caso prefiero este lado del mundo. Los aquí ensalzados y añorados muñequitos rusos representan para mi una época atroz de mi vida y la de muchos que ni siquiera pudieron ver esos muñequitos en la TV cubana porque estaban y están vilmente encarcelados en las prisiones del Tirano, ah y quiero y sigo queriendo tanto a mi país: Cuba, como vosotros pero mejor sin muñequitos rusos! (Comentario dejado por un3gracias, 17 septiembre 2006, 5:09 a. m.)}

\footnotetext{
11 CAME: Consejo de Ayuda Mutua Económica, organización de cooperación económica entre la URSS y los países socialistas.

12 En mayúsculas en el original.
} 
Hay que señalar además que entre los habituales es posible encontrar comentarios que se resisten a concebir el pasado caribeño o la situación actual de Cuba como una utopía defendible, pero que; sin embargo, mantienen el vínculo afectivo con los muñes y los recuerdos compartidos de su vida anterior durante el período soviético. En ese sentido, vale citar a Susannah Radstone y Katherine Hopkins, quienes afirman que la idea de la memoria como una herramienta para impugnar versiones "oficiales" del pasado, también muda de la contraposición de la verdad subordinada a la mentira dominante, a una preocupación con el modo en que un determinado evento puede, varias veces y por varias razones, ser promovido, reformulado o silenciado (2003: 8, mi traducción).

Sería pertinente considerar que en lo que podemos denominar la blogosfera cubana, existían otros blogs más orientados hacia una revisión crítica del pasado desde la óptica de la diáspora. Además, la posterior emergencia de las redes sociales han posibilitado un espacio mayor y más inmediato para la aparición y desarrollo de esferas públicas digitales en las que discusiones sobre el pasado, la memoria y la nostalgia, pueden abordarse fuera de los límites de un blog.

Luego de la popularidad de Muñequitos Rusos y de su impacto dentro y fuera de Cuba, el período soviético y los animados han vuelto a ocupar espacios de debate y a centrar investigaciones académicas en la isla. Asimismo, varias producciones audiovisuales ${ }^{13}$ se han enfocado al análisis de la influencia de la URSS y de los dibujos animados. Sin embargo, lejos de ser un fenómeno local y específico de Cuba, la nostalgia por los muñequitos socialistas ha aparecido hasta en la propia Rusia $^{14}$.

Como en Alemania con el conocido fenómeno de la Ostalgie (Estalgia), la nostalgia se materializa en productos y objetos para el consumo, por ejemplo, en bolsas y camisetas del proyecto Chamakovic en La Habana, comercializados en moneda convertible, lo que sugiere que tales iniciativas más que al turismo internacional, se destinan a los cubanos de la diáspora o al sector de esta más activo en los viajes a Cuba. Como asegura Darwin Fornés, de Chamakovic, en entrevista con Charly Morales (2013), "la nostalgia vende”. Series de muñequitos y películas comunes a las generaciones antes mencionadas también pueden adquirirse en Miami, donde la nostalgia también se comercializa y forma parte de lo que pudiéramos llamar un mercado nostálgico bajo demanda, pues desde hace años existen en el sur de La Florida, establecimientos donde adquirir productos audiovisuales o mercadería relativa a materiales de entretenimiento concebidos en los años 80 y 90 , así como programas de televisión y series que actualmente se exhiben en los canales de la isla.

En las redes sociales y el blog, sin embargo, la nostalgia se "produce”, pues encuentra un espacio en el que las vivencias y experiencias comunes del pasado se comparten en la gran mayoría de los casos, sin que medie un interés económico. Es con este intercambio de recuerdos que los

\footnotetext{
${ }^{13}$ Varias producciones sobre el período soviético son analizadas por Reyes (2011) y Puñales Alpízar (2012).

${ }^{14}$ Ver Martínez (2008).
} 
emigrados crean vínculos afectivos transnacionales que favorecen en ellos la identificación respecto a sí mismos, sus compatriotas, al país de origen y al de acogida.

\section{Conclusiones}

En este artículo he analizado la importancia del blog Muñequitos Rusos y sus interacciones, como incentivo para la vinculación afectiva trasnacional entre emigrados cubanos. Consumidos y compartidos en línea, gracias a las plataformas digitales, los dibujos animados pueden considerarse parte de los marcadores identitarios de más de una generación nacida en la isla, a la que también podemos calificar como comunidad sentimental soviético-cubana.

Desde la diáspora, el pasado -caracterizado en esta ocasión como el relativo al período de influencia soviético en la Cuba revolucionaria - se convierte en un elemento aglutinador y en el centro hacia el cuál los emigrados, a través de las posibilidades de las nuevas tecnologías de la información, dirigen sus nociones de pertenencia. La autora del blog y su audiencia se interesan por construir una narrativa de la nostalgia, sin embargo esta no se limita a identificar y compartir sus memorias, sino que a través de la narración de la autora del blog y las intervenciones de su lectores/ seguidores, acudimos a la creación de nuevas memorias.

Mediante las interacciones del blog, los lectores/seguidores comparten recuerdos sobre un pasado común que surgen del poder evocativo de los muñequitos rusos. La vida anterior en la isla se rememora y revisa no solamente a través de la narración colectiva de las anécdotas contadas por los animados del otrora campo socialista, sino también mediante el recuento de prácticas culturales y generacionales asociadas con el acto mismo de visualizar dichos productos mediáticos. El pasado común también se construye y reconstruye en Internet con una visión más crítica, pues se remarcan aquellos elementos ideológicos del discurso oficial que contribuyeron a una representación colectiva del país de origen centrada en un limitado concepto de patria.

Atraídos por la posibilidad de identificarse con la memoria de un pasado común en la isla, los visitantes se topan con los recuerdos y su contexto. Como he demostrado, para los emigrados cubanos rememorar puede tornarse, desde la diáspora, una acción colectiva con el aporte de un repertorio más plural y diverso de experiencias vividas en el país de origen. Los emigrantes aportan nuevas narraciones asociadas con el período soviético y recuperan/revisan las nociones sobre identidad y nación previamente aprehendidas en Cuba. Dicho proceso contribuye además a que los participantes/emigrados rechacen nociones esencialistas asociadas a términos como la identidad y la nación de origen. 


\section{Bibliografía citada}

Berg, Mette (2011). Diasporic generations: Memory, politics and nation among Cubans in Spain. Oxford: Berghahn Books.

Brah, Avtar (1996). Cartographies of diaspora: contesting identities. London: Routledge.

Bobes, Velia Cecilia. "Diáspora, ciudadanía y contactos transnacionales” Nueva Sociedad. 242 (noviembre-diciembre), (2012): 106-122.

Casal, Lourdes. (1971) El caso Padilla: literatura y revolución en Cuba. Miami: Ediciones Universal.

Cohen, Robin (1997). Global Diasporas: an introduction. London: UCL Press.

Duong, Paloma. "Bloggers Unplugged: Amateur Citizens, Cultural Discourse, and Public Sphere in Cuba" Journal of Latin American Cultural Studies: Travesía. 22 (4), (2013): 375-397.

Erll, Astrid (2011). Memory in culture. Londres: Palgrave Macmillan.

García, María Cristina (2007). "The Cuban population of the United States: an introduction". O’Reilly Herrera, Andrea (ed.) Cuba: Idea of a nation displaced. Nueva York: State University of New York Press: 75-89.

Halbwachs, Maurice (1992). On collective memory. Chicago: University of Chicago Press.

Hernández-Reguant, Ariana (2009) "Multicubanidad”. Hernández-Reguant, Adriana (ed.) Cuba in the Special Period: Culture and ideology in the 1990s. Nueva York: Palgrave Macmillan: 69-88.

Jácome, Aurora (2012). "The Muñequitos Rusos generation”. Loss, Jacqueline y Prieto, José Manuel (eds.) Caviar with rum: Cuba-URSS and the post-soviet experience. Nueva York: Palgrave Macmillan: 27-36.

Kapcia, Antoni (2000). Cuba: Island of dreams. Oxford: Berg.

Loss, Jacqueline. "Vintage Soviets in post-Cold War Cuba". Mandorla: Nueva Escritura de las Américas 7 (2003): 79-84.

Martínez, Francisco. “El regreso de los ‘muñequitos’ rusos”. Soitu.es (2008).

Morales Valido, Charly. “¡Nu Pogodí! Regresan los muñequitos rusos” OnCuba Magazine (2013).

Oficina Nacional de Estadísticas (2014). Anuario estadístico de Cuba: empleo y salarios. 
Puñales Alpízar, Damaris (2012). Escrito en cirílico: el ideal soviético en la cultural cubana posnoventa. Santiago: Editorial Cuarto Propio.

Radstone, Susannah y Hodgkin, Katharine (2003). "Introduction: contested pasts". Radstone, Susannah y Hodgkin, Katharine (eds.) The politics of memory. Londres: Routledge:1-22.

Reyes, Dean Luis. "Ostalgie caribeña: saudade postsoviética en el audiovisual cubano contemporáneo”. ArtCultura, 13, 22 (2011): 61-70.

Saffran, William. "Diasporas in modern societies: myths of homeland and return". Diaspora, 1, 1, (1991): 83-99.

Tölölyan, Khachid. "The nation-state and its others: in lieu of a preface”. Diaspora, 1, 1, (1991): 3-7.

Van Dijck, José (2007). Mediated memories in the digital age. Stanford: Stanford University Press. 